\title{
Is GETUP Helpful and Relevant in a Resource Poor Setting Like Nepal?
}

\author{
Ajay Singh Thapa ${ }^{1}$
}

Published online: 19 November 2015

(C) American College of Medical Toxicology 2015

Emergency medicine is an emerging specialty worldwide and is taking a leading role in caring for critically ill and undifferentiated patients. Nepal is one of the South Asian countries that have recently started an emergency medicine training program. Medical toxicology services are currently provided by emergency physicians and other doctors working in the emergency department (ED). However, the lack of trained specialists in medical toxicology means acutely poisoned patients may not receive the same level of care offered in developed nations. Demand for healthcare and patient expectations are high in the poisoned patients and families in Nepal. Currently, there are no formal training programs or educational opportunities in medical toxicology in Nepal.

Poisoning is a frequent method of deliberate self-harm in Nepal, of which organophosphate poisoning is the most common [1]. The $10-20 \%$ case fatality rate found with selfpoisoning in the developing world differs markedly from the $0.5 \%$ found in the west [2]. The lack of knowledge and experience has contributed significantly to mortality in young poisoned patients in Pakistan [3]. A study done in Pakistan showed that a short period of clinical training in medical toxicology improved emergency physicians' knowledge about the management of poisoned patients [4]. Education is essential to improving care in these regions. For example, first aid training has had a huge impact on changing the knowledge and practice of the medical staff in the management of snake bite and has decreased mortality [5].

New emergency physicians and doctors working in EDs need to receive continual education in medical toxicology to

Ajay Singh Thapa

drajay_thapa@yahoo.com

1 Grande Int. Hospital, Kathmandu, Nepal improve patient care. This could be made possible through either online distance courses or onsite teaching. Online teaching by GETUP (Global Educational Toxicology Uniting Project) is one of the solutions for the resource poor setting [6]. GETUP is an initiative supported by the American College of Medical Toxicology to facilitate education in medical toxicology using the Internet to connect healthcare providers in developed and developing countries. Potential barriers to this include electricity shortages, poor Internet connectivity, and lack of familiarity with the computer conferencing software.

The creation of a medical toxicology center and development of a curriculum relevant to the local setting would be a long-term solution; however, this will likely require ongoing on-site expertise and hospital resources. GETUP may be instrumental in providing this expertise and knowledge to a resource poor setting like Nepal, and may help to train current healthcare providers caring for poisoned patients. In the future, this model may be able to be applied to other medical specialties.

\section{References}

1. Khadka SB. A study of poisoning cases in emergency. Kathmandu Med Coll Teach Hosp. 2005;3(4):388-91.

2. Eddleston $\mathrm{M}$ et al. The hazards of gastric lavage for intentional selfpoisoning in a resource poor location. Clin Toxicol (Phila). 2007;45(2):136-43.

3. Siddiqui EU et al. Factors associated with hydrocarbon ingestion in children. JPMA. 2008;58:608-12.

4. Khan NU et al. Importance of clinical toxicology teaching and its impact in knowledge: sharing experience from a workshop. JPMA. 2013;63(11):1379-82.

5. Pandey DP et al. Impact of first aid training in management of snake bite victims in Madi Valley. J Nepal Health Res Counc. 2010;8(1):59.

6. Carney PA et al. Computer use among community-based primary care physician preceptors. JAMA. 2004;79(6):580. 